\title{
Slaughterhouse blood as a perfusate for studying myocardial function under ischemic conditions
}

\section{K. Bendjelid ${ }^{1}$, E. Canet ${ }^{1,2}$, Y. Gasche ${ }^{4}$, \\ $X$. Andre-Fouet ${ }^{3}$, \\ D. Revel ${ }^{2}$ and M. Janier ${ }^{1}$}

${ }^{1}$ Medical Research Centre with Positron Emission (CERMEP), Lyon, France

${ }^{2}$ CREATIS UMR 5515 CNRS, and ${ }^{3}$ Claude Bernard-Lyon I University, Louis Pradel

Thoracic and Cardiovascular Hospital, Lyon, France

${ }^{4}$ Surgical Intensive Care Division, University Hospitals of Geneva, Geneva, Switzerland
Correspondence

K. Bendjelid

Chef de Clinique

Division des Soins Intensifs

Chirurgicaux

Hôpitaux Universitaires de Genève

CH-1211 Genève 14

Switzerland

Fax: +41-22-382-7455

E-mail: karim.bendjelid@hcuge.ch

Some of these data have been presented at the III Congress of GRRC (Groupe de Réflexion sur la Recherche Cardio-vasculaire), Montpellier, France, April 26-27, 2001. Arch. Mal. Coeur., 94: 380, 2001 (No. 27-5)

Received May 10, 2002 Accepted October 14, 2002

\begin{abstract}
Metabolic studies using the in vitro non-recirculating blood-perfused isolated heart model require large volumes of blood. The present study was designed to determine whether heterologous pig blood collected from a slaughterhouse can be used as perfusate for isolated pig hearts perfused under aerobic and constant reduced flow conditions. Eight isolated working pig hearts perfused for $90 \mathrm{~min}$ at a constant flow of $1.5 \mathrm{ml} \mathrm{g}^{-1} \mathrm{~min}^{-1}$ with non-recirculated blood diluted with KrebsHenseleit bicarbonate buffer at a hematocrit of $23 \%$ were compared to eight hearts subjected to the same protocol but perfused only with Krebs-Henseleit bicarbonate buffer solution. Hearts were paced at 100 bpm and subjected to aerobic perfusion at $38^{\circ} \mathrm{C}$. Hearts were weighed before perfusion and at the end of the experiment and the results are reported as percent weight gain (mean $\pm \mathrm{SD}$ ). Comparisons between groups were performed by the Student $t$-test $(\mathrm{P}<0.05)$. After $90 \mathrm{~min}$ of perfusion with modified Krebs-Henseleit, perfused hearts presented a larger weight gain than blood-perfused hearts (39.34 \pm 9.27 vs 23.13 $\pm 5.42 \%, \mathrm{P}=0.003)$. Left ventricular end-diastolic pressure was higher in the modified Krebs-Henseleit-perfused group than in the blood group $(2.8 \pm 0.4$ vs $2.3 \pm 0.3 \mathrm{mmHg}$, respectively, $\mathrm{P}=0.01)$. We conclude that heterologous blood perfusion, by preserving a more physiological myocardial water content, is a better perfusion fluid than modified Krebs-Henseleit solution for quantitative studies of myocardial metabolism and heart function under ischemic conditions.
\end{abstract}

\section{Introduction}

Isolated perfused heart preparations provide controlled conditions for the study of myocardial function and metabolism. Most studies utilize a hemoglobin-free perfusate, such as Krebs-Henseleit solution, which requires high arterial oxygen tension (1) and a high coronary perfusion rate (2). Although
Key words

- Myocardium

- Ischemia

- Erythrocytes

- Edema

- Reperfusion injury
Krebs-Henseleit-perfused isolated heart experimentations have the advantage of low cost, simplicity and avoidance of thrombus formation, these preparations are unphysiological because they are devoid of many of the vital components of blood. On the other hand, recent studies have shown that crystalloid-perfused hearts present significantly more edema than blood-perfused hearts after 
ischemia and reperfusion $(3,4)$. Furthermore, increased myocardial water content compromises left ventricular function and contributes to ultrastructural damage to the myocardium (5).

Generally, metabolic studies are performed using an in vitro model of non-recirculating heart perfusion which requires a large perfusate volume, preventing blood utilization. In this context, blood obtained from slaughterhouses, available in large quantities, may be an interesting alternative. The present study was designed to quantify and compare the weight gain of working isolated pig hearts perfused with Krebs-Henseleit solution or with blood collected from a slaughterhouse. We have developed a bloodperfused working isolated pig heart preparation adapted from the work of Ferrera et al. (6) in order to investigate the protective effect of a heterologous blood perfusate on the appearance of edema during a prolonged $(90$ min) perfusion under ischemic conditions.

\section{Material and Methods}

This study conforms with the Guide for the Care and Use of Laboratory Animals published by the US National Institutes of Health (NIH Publication \# 85-23, revised in 1996).

\section{Perfusate composition}

A modified Krebs-Henseleit bicarbonate buffer (7) ( $\mathrm{pH} 7.4$; temperature, $\left.38^{\circ} \mathrm{C}\right)$ was prepared to obtain the following final concentrations: $118 \mathrm{mM}$ sodium chloride, 4.7 $\mathrm{mM}$ potassium chloride, $2.4 \mathrm{mM}$ calcium chloride, $1.2 \mathrm{mM}$ potassium phosphate, 0.5 $\mathrm{mM}$ calcium-EDTA, $11 \mathrm{mM}$ glucose, 25 $\mathrm{mM}$ sodium hydrogen carbonate, and 1.2 mM magnesium sulfate. The modified KrebsHenseleit-perfused group was oxygenated with an oxygenator (Monolyth, Sorin 050162P7852, Saluggia, Italy) using 95\% oxygen plus $5 \%$ carbon dioxide to achieve a partial arterial oxygen pressure $>400 \mathrm{mmHg}$.

For each experiment carried out on the group of hearts perfused with blood, 10,000 $\mathrm{ml}$ of blood were collected into a container from 4 to 5 pigs at a slaughterhouse (Mornant, France). The pigs were exsanguinated by incision of the carotid artery after paralyzing by an electric current. Next, $5000 \mathrm{U}$ heparin per $1000 \mathrm{ml}$ blood was added to the container. The blood was filtered and stored at $4^{\circ} \mathrm{C}$ for a maximum of $1 \mathrm{~h}$ and then diluted with the modified Krebs-Henseleit buffer to obtain a hematocrit of $23 \%$. Blood perfusate oxygenation was carried out with the same oxygenator using $95 \%$ oxygen plus $5 \%$ carbon dioxide to achieve an arterial partial oxygen pressure of $140 \mathrm{mmHg}$. The perfusion apparatus maintained the coronary perfusate at $38^{\circ} \mathrm{C}$.

\section{Isolated pig heart preparation}

In a first step, the preparation was set up according to the methods of Langendorff (8) and Kobayashi and Neely (9) for isolated heart preparations. In a second step, we selectively cannulated the right and left main coronary arteries to precisely control regional myocardial perfusion separately from cardiac function.

Farm pigs (20-25 kg) were fasted overnight before surgery. Fifteen minutes before anesthesia, $50 \mathrm{mg}$ droperidol (Droleptan ${ }^{\circledR}$ ) was injected intramuscularly. Intravenous anesthesia was then performed with thiopental $\left(4 \mathrm{mg} / \mathrm{kg}\right.$, Nesdonal $\left.{ }^{\circledR}\right)$. Mechanical ventilation (Monal; minute ventilation, 4 liters; respiratory rate, $13 ; 50 \%$ oxygen) was provided after rapid tracheotomy using a No. 75 endotracheal tube. Through a sternotomy, the heart was harvested after aortic clamping and infusion of $500 \mathrm{ml}$ cold $\left(4^{\circ} \mathrm{C}\right) \mathrm{St}$. Thomas No. 2 cardioplegia solution (Laboratoires Aguettant, Lyon, France) (10). Next, the heart was weighed, the pulmonary artery cannulated, the inferior and superior vena cava ligated, and the aorta fixed onto the system. 
The left atrium was maintained open to allow drainage of the Thebesius effluent. A latex balloon was inserted into the left ventricle, inflated with water and fixed on the mitral valve annulus. Proximal left and right coronary arteries were dissected and cannulated selectively. The preparation time (from excision to reperfusion) for the isolated heart preparation ranged from 20 to $25 \mathrm{~min}$. During this preparation, hearts were maintained in cold $\left(4^{\circ} \mathrm{C}\right) \mathrm{St}$. Thomas solution. Next, the aorta was fixed onto the perfusion system and hearts were reperfused at $38^{\circ} \mathrm{C}$.

\section{Experimental protocols}

A total of 16 hearts were perfused either with the modified Krebs-Henseleit solution as a perfusate $(\mathrm{N}=8)$ or with the blood perfusate $(\mathrm{N}=8)$ using an electromagnetic Gear pump (MCP-Z, Ismatec, Zurich, Switzerland). A constant flow rate of $1.5 \mathrm{ml} \mathrm{g}^{-1}$ $\mathrm{min}^{-1}$ was applied to each heart group for 90 min. Both perfusion systems consisted of a non-recirculating apparatus and the coronary effluent was collected from the pulmonary artery catheter. Two epicardial electrodes were positioned through the right atrium, and hearts were paced at a constant rate of $100 \mathrm{bpm}$ throughout the entire protocol. The intraventricular latex balloon was filled with a volume of saline to produce an end-diastolic pressure of $5 \mathrm{mmHg}$. It was then connected to an artificial heart system (Abiomed Inc., Danvers, MA, USA), which permits the adaptation of preload $(3 \mathrm{mmHg})$ and afterload $(70 \mathrm{mmHg})$. The pressure transducer system used was a rigid fluid-filled cannula connected to a pressure transducer (Medex, SX 620449 CST, Annecy-le-Vieux, France). Myocardial oxygen consumption was calculated as the product of coronary flow and coronary arteriovenous oxygen content difference. At the end of the experiment, hearts and excess fluid were gently removed. The balloon and the pulmonary artery catheter were removed and hearts were weighed.

\section{Statistical analysis}

Descriptive statistics such as proportions, means, and standard deviations were used to summarize the results. The paired Student $t$ test was used to compare heart weights before and after perfusion for each group. The unpaired Student $t$-test was used to compare heart weight, heart weight gain, left ventricular end-diastolic pressures and left ventricular developed pressures between the two groups. Differences were considered significant when $\mathrm{P}<0.05$.

\section{Results}

The substrate composition of the blood coming from the slaughterhouse is shown Table 1. During the experiment, we monitored the oxygen uptake of the blood-perfused and modified Krebs-Henseleit solution-perfused preparations (Table 1). Coronary perfusion pressures of modified KrebsHenseleit- and blood-perfused hearts increased regularly throughout the experiment. Heart rate (mean $\pm \mathrm{SD}$ ) was stable at $100 \pm 2$ bpm during this 90 -min period. After $90 \mathrm{~min}$

Table 1. Composition of slaughterhouse mixed blood, modified Krebs-Henseleit (KH) perfusate and diluted blood perfusate

\begin{tabular}{lccr}
\hline Component & Blood & $\begin{array}{c}\text { Modified } \mathrm{KH} \\
\text { perfusate }\end{array}$ & $\begin{array}{c}\text { Diluted blood } \\
\text { perfusate }\end{array}$ \\
\hline $\mathrm{pH}$ & $7.43 \pm 0.02$ & $7.36 \pm 0.09$ & $7.39 \pm 0.03$ \\
$\mathrm{p}_{\mathrm{aCO}}(\mathrm{mmHg})$ & - & $38.0 \pm 4.1$ & $36.6 \pm 4.2$ \\
$\mathrm{paO}_{2}(\mathrm{mmHg})$ & - & $421.0 \pm 22.0$ & $147.0 \pm 9.0$ \\
$\mathrm{O}_{2}$ uptake $\left(\mu \mathrm{min}^{-1} \mathrm{~g}^{-1}\right)$ & - & $136.0 \pm 18.0$ & $163.0 \pm 17.0$ \\
$\mathrm{Na}^{+}(\mathrm{mM})$ & $144.0 \pm 0.9$ & $125.0 \pm 1.4$ & $128.0 \pm 1.1$ \\
$\mathrm{~K}^{+}(\mathrm{mM})$ & $3.5 \pm 0.11$ & $4.0 \pm 0.13$ & $4.3 \pm 0.19$ \\
$\mathrm{Ca}^{2+}(\mathrm{mM})$ & $1.31 \pm 0.06$ & $2.53 \pm 0.11$ & $2.61 \pm 0.16$ \\
$\mathrm{Cl}^{-}(\mathrm{mM})$ & $98.0 \pm 1.1$ & $102.0 \pm 0.9$ & $105.0 \pm 1.1$ \\
$\mathrm{Hematocrit}(\%)$ & $36.0 \pm 1.1$ & 0.0 & $23.0 \pm 1.9$ \\
$\mathrm{Hemoglobin}(\mathrm{g} / \mathrm{dl})$ & $12.1 \pm 0.13$ & 0.0 & $8.3 \pm 0.4$ \\
Glucose $(\mathrm{mM})$ & $9.0 \pm 0.25$ & $11.0 \pm 0.4$ & $11.0 \pm 0.6$ \\
Urea $(\mathrm{mM})$ & $7.0 \pm 1.0$ & $0.2 \pm 0.01$ & $2.5 \pm 0.5$ \\
Proteins $(\mathrm{g} / \mathrm{l})$ & $51.0 \pm 1.8$ & 0.0 & $29.0 \pm 0.7$ \\
\end{tabular}

Blood was obtained from 4-5 pigs at a slaughterhouse. Blood was diluted with $\mathrm{KH}$ buffer to obtain a hematocrit of $23 \% . \mathrm{O}_{2}$ uptake: myocardial oxygen consumption (measured by Fick principle). All values are reported as means \pm SD for 8 samples. 
of perfusion, left ventricular end-diastolic pressure (mean $\pm \mathrm{SD}$ ) was significantly higher in the modified Krebs-Henseleit-perfused group than in the blood group (2.8 \pm 0.4 vs $2.3 \pm 0.3 \mathrm{mmHg}$, respectively, $\mathrm{P}=$ 0.01). Left ventricular developed pressure was significantly higher in the blood-perfused group than in the modified KrebsHenseleit-perfused group (73.3 \pm 1.5 vs 70.2 $\pm 1.4 \mathrm{mmHg}$, respectively, $\mathrm{P}=0.0008)$. The arteriovenous difference between the $\mathrm{pO}_{2}$ measured in the arterial line and the $\mathrm{pO}_{2}$ measured in the coronary return remained constant throughout the experiment for both perfusates, demonstrating a good extraction, hence a good-quality myocardial oxygenation. The mean \pm SD weight of modified Krebs-Henseleit- and blood-perfused hearts was $148.94 \pm 20.59$ and $143.99 \pm 19.27 \mathrm{~g}$, respectively, before perfusion $(\mathrm{P}=0.63)$. For both groups, heart weight increased after perfusion $(\mathrm{P}<0.0001)$. After $90 \mathrm{~min}$ of perfusion, weight gain was higher in the modified Krebs-Henseleit solution-perfused hearts than in the blood-perfused hearts $(39.34 \pm$ 9.27 vs $23.13 \pm 5.42 \%$, respectively, $\mathrm{P}=$ 0.003; Figure 1).

\section{Discussion}

This study compares for the first time the weight gain of working isolated pig hearts perfused with crystalloid solution (modified Krebs-Henseleit) versus heterologous blood obtained from the slaughterhouse. The results indicate that heterologous blood, be-

Figure 1. Heart weight gain after 90 min of perfusion. Hearts were perfused with modified Krebs-Henseleit solution ( $N=8$ ) or blood perfusate $(\mathrm{N}=8)$. The horizontal lines indicate the mean. ${ }^{*} P<0.05$ compared to blood perfusate (Student $t$-test).

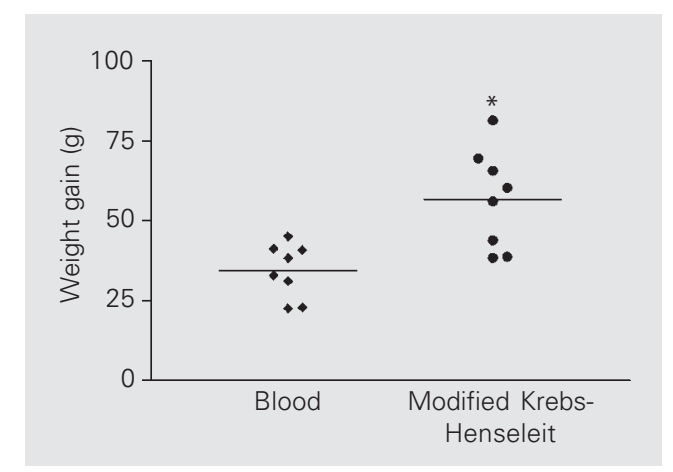

cause of a lower myocardial water accumulation, is more physiological than the KrebsHenseleit solution after prolonged perfusion under ischemic conditions. Moreover, in parallel to the greater extent of edema in the Krebs-Henseleit group, greater deterioration in the contractile performance was observed, as indicated by the left ventricular pressure measurements. Myocardium was perhaps better preserved from edema by the osmotic and oncotic profile of blood in contrast to modified Krebs-Henseleit perfusion (2). Heterologous blood-perfused isolated hearts have been used in the past (11-13) but, in those studies no comparisons of weight gain or water content was performed. On the other hand, although several studies $(3,4,14)$ support the notion that blood is a superior perfusate to crystalloid solutions particularly when water content is considered, to our knowledge, no study has used heterologous blood from a slaughterhouse.

Metabolic substrates and energetic stability were not analyzed in this study because we were testing the feasibility of the heterologous blood perfusion in this model. Nevertheless, heart rate, myocardial oxygenation, left ventricular end-diastolic pressure, and left ventricular developed pressure were recorded throughout the experiment. All hearts were paced at $100 \mathrm{bpm}$ and perfused at a constant reduced flow to prevent the occurrence of any difference in myocardial edema between the two groups resulting from variations of these parameters $(15,16)$. We used a higher arterial oxygen tension in the modified Krebs-Henseleit solution as a perfusate than in the blood perfusate (421 \pm 22 vs $147 \pm 9 \mathrm{mmHg}$ ) because these myocardial oxygen levels are considered adequate to meet metabolic demands of working isolated hearts according to the type of perfusion (blood versus crystalloid) (1), without influencing myocardial water content (17). Interestingly, the data indicate that the greater edema observed in the Krebs-Henseleit group seemed not to be due to hypoxia since arteri- 
al $\mathrm{pO}_{2}$ was adequate, but to other ischemiaassociated factors.

In this study, we were able to separate coronary perfusion from contractile function using a latex balloon inserted into the left ventricle and selective cannulation of coronary vessels. Thus, our model should be useful for metabolic studies. In this mode, an accurate quantification of metabolic balance is possible since the same perfusate passes only once through the heart, preventing the accumulation of metabolic substances. However, this system requires large quantities of blood, impossible to collect from a single animal. In this setting, the slaughterhouses are an alternative for obtaining large volumes of blood and, despite the mix of blood from different animals, no hemolysis complications were noted in the present study. This may be explained by the lack of natural antibodies against blood group factors in pigs (18).

\section{Study limitation}

A high oxygen tension model normally used for studying myocardial hypoxia was employed. Indeed, myocardial oxygen consumption $\left(136 \pm 18 v s 163 \pm 17 \mu \mathrm{min}^{-1} \mathrm{~g}^{-1}\right.$ for modified Krebs-Henseleit solution and blood, respectively) ensures that the edema produced in the modified Krebs-Henseleit group is not the result of hypoxia induced by the experimental design. However, we subjected all isolated hearts to the same reduced coronary flow, a procedure that probably prevented any difference in myocardial edema between groups resulting from variations of perfusion. Furthermore, compared to other studies $(3,4)$, the present protocol permitted us to determine if the difference in myocardial edema between the modified Krebs-Henseleit group and the heterologous blood group existed when isolated hearts were subjected to ischemic conditions.

In the present study, we measured only weight gain but not water content $(3,4)$. Indeed, direct assessment of edema formation by estimation of changes in myocardial water content is more accurate than estimation of weight gain. Nevertheless, continuous weight gain can be extrapolated to edema formation since excess fluid surrounding the heart was gently removed after perfusion. In addition, in previous studies on isolated rabbit lungs perfused with blood, the combined histologic score of lung hemorrhage was correlated with weight gain $(19,20)$.

Our results demonstrate that weight gain by working isolated pig hearts, a surrogate of myocardial edema formation, increased more after modified Krebs-Henseleit solution perfusion than after heterologous blood perfusion under ischemic conditions. Since the presence of myocardial edema represents one of the crucial events in the pathophysiology of cardiac dysfunction following reperfusion injury, heterologous blood perfusate obtained from a slaughterhouse should be used as an alternative to modified KrebsHenseleit solution as a perfusate for quantitative experimental studies of myocardial metabolism and heart function. Moreover, an essential goal of using blood as a perfusate instead of crystalloids is to mimic the in vivo situation. Indeed, including the interaction between endothelial cells and blood elements such as erythrocytes, platelets and leukocytes should be attractive to reduce heart reperfusion injury in working heart preparations.

\section{Acknowledgments}

The authors gratefully acknowledge Cendrine Casali and Annie Desenfant for technical assistance. The authors also thank Jean Francois Obadia and René Ferrera for helpful advice regarding the preparation, and the Abattoir of Pavière (Mornant, France) for providing the blood. 


\section{References}

1. Friedman BJ, Grinberg OY, Grinberg SA \& Swartz HM (1997). Myocardial oxygen tension in isolated erythrocyte-perfused rat hearts and comparison with crystalloid media. Journal of Molecular and Cellular Cardiology, 29: 2855-2858.

2. Bergmann SR, Clark RE \& Sobel BE (1979). An improved isolated heart preparation for external assessment of myocardial metabolism. American Journal of Physiology, 236: H644-H661.

3. Deng Q, Scicli AG, Lawton C \& Silverman NA (1995). Coronary flow reserve after ischemia and reperfusion of the isolated heart. Divergent results with crystalloid versus blood perfusion. Journal of Thoracic and Cardiovascular Surgery, 109: 466-472.

4. Qiu Y \& Hearse DJ (1992). Comparison of ischemic vulnerability and responsiveness to cardioplegic protection in crystalloid-perfused versus blood-perfused hearts. Journal of Thoracic and Cardiovascular Surgery, 103: 960-968.

5. Barsotti A, Di Napoli P, Dini FL, Soccio M, Di lorio P, Gallina S, Di Muzio M \& Modesti A (1998). Effect of acute increase of interstitial myocardial fluid on ventricular function in isolated working rat hearts. Journal of Medicine, 29: 137-158.

6. Ferrera R, Marcsek P, Larese A, Girard C, Guidollet J, Dittmar A \& Dureau G (1993). Comparison of continuous microperfusion and cold storage for pig heart preservation. Journal of Heart and Lung Transplantation, 12: 463-469.

7. Krebs HA \& Henseleit K (1932). Untersuchungen über die Harnstoffbildung im Tierkörper. Hoppe-Seyler's Zeitschrift für Physiologische Chemie, 210: 33-66.

8. Langendorff O (1895). Untersuchungen am überlebenden Säugertierherzen. Pflügers Archiv, 61: 291-332.

9. Kobayashi K \& Neely JR (1979). Control of maximum rates of glycolysis in rat cardiac muscle. Circulation Research, 44: 166-175.

10. Obadia JF, Casali C, Chassignolle JF \& Janier M (1997). Mitral subvalvular apparatus: different functions of primary and secondary chordae. Circulation, 96: 3124-3128.

11. Duvelleroy MA, Duruble M, Martin JL, Teisseire B, Droulez J \& Cain M (1976). Blood-perfused working isolated rat heart. Journal of
Applied Physiology, 41: 603-607.

12. Deng Q, Scicli AG, Lawton C \& Silverman NA (1994). A simplified blood-perfused isolated heart preparation. Journal of Thoracic and Cardiovascular Surgery, 108: 1158-1159.

13. Chen V, Chen YH \& Downing SE (1987). An improved isolated working rabbit heart preparation using red cell enhanced perfusate. Yale Journal of Biology and Medicine, 60: 209-219.

14. Podesser BK, Hallstrom S, Schima H, Huber L, Weisser J, Kroner A, Furst W \& Wolner E (1999). The erythrocyte-perfused "working heart" model: hemodynamic and metabolic performance in comparison to crystalloid perfused hearts. Journal of Pharmacological and Toxicological Methods, 41: 9-15.

15. Schertel ER, Daye RM, McClure DE, Lai T, Miyamoto M \& Myerowitz PD (1997). Mechanical workload-myocardial water content relationship in isolated rat hearts. American Journal of Physiology, 273: $\mathrm{H} 271-\mathrm{H} 278$.

16. Rubboli A, Sobotka PA \& Euler DE (1994). Relations between acute myocardial oedema, coronary vascular resistance and left ventricular mechanics in isolated rat heart. Cardiologia, 39: 497-505

17. Askenasy N \& Navon G (1997). Continuous monitoring of intracellular volumes in isolated rat hearts during normothermic perfusion and ischemia. Journal of Magnetic Resonance, 124: 42-50.

18. Gorge G, Erbel R, Dobbertin A, Hanggi M, Hake U \& Meyer J (1994). Isolated in vitro perfusion of pig hearts obtained from the abattoir: an alternative to animal experiments? European Heart Journal, 15: 851857.

19. Broccard AF, Hotchkiss JR, Kuwayama N, Olson DA, Jamal S, Wangensteen DO \& Marini JJ (1998). Consequences of vascular flow on lung injury induced by mechanical ventilation. American Journal of Respiratory and Critical Care Medicine, 157: 1935-1942.

20. Broccard AF, Hotchkiss JR, Suzuki S, Olson D \& Marini JJ (1999). Effects of mean airway pressure and tidal excursion on lung injury induced by mechanical ventilation in an isolated perfused rabbit lung model. Critical Care Medicine, 27: 1533-1541. 